See discussions, stats, and author profiles for this publication at: https://www.researchgate.net/publication/333003287

\title{
Time Perspective and Career Decision-Making Self-Efficacy: A Longitudinal Examination Among Young Adult Students
}

Article in Journal of Career Development · May 2019

DOI: $10.1177 / 0894845319847292$

2 authors, including:

Carlos A Almenara

Universidad Peruana de Ciencias Aplicadas (UPC)

29 PUBLICATIONS 69 CITATIONS

SEE PROFILE

Some of the authors of this publication are also working on these related projects:

Project THINLINE View project

The Breast Size Satisfaction Survey: An International, Collaborative Project View project 
Time Perspective and Career Decision-Making Self-Efficacy: A Longitudinal Examination Among Young Adult Students
(C) Curators of the University of Missouri 2019 Article reuse guidelines: sagepub.com/journals-permissions DOI: $10.1177 / 0894845319847292$ journals.sagepub.com/home/jcd

(SAGE

\author{
Lucia Kvasková' and Carlos A. Almenara ${ }^{2}$
}

\begin{abstract}
This longitudinal study examined the relationship between Zimbardo time perspectives (TPs) and career decision-making self-efficacy (CDMSE). In total, I,753 young adults participated in the longitudinal study. For the present study, we selected only participants who were students and provided information on TPs, CDMSE, and sociodemographic characteristics $(n=492, M=22.97$ years, $S D=$ I.32, $82.9 \%$ women). The results of multilevel modeling showed that future orientation and presenthedonistic TPs were positively related to CDMSE, whereas present-fatalistic and past-negative TPs were negatively related to CDMSE. These findings indicate that besides the beneficial effect of widely studied future TP, the negative role of past-negative and present-fatalistic TPs should be considered in connection with the career development of emerging adults.
\end{abstract}

\title{
Keywords
}

Zimbardo time perspectives, career decision-making self-efficacy, emerging adults

Settling on a career is a major developmental task for emerging adults (i.e., young people approximately 18-30 years of age; Arnett, 2014). During emerging adulthood, individuals are involved in career preparation, which involves managing educational demands, exploring information about careers, formulating career goals, and developing their career identity based on their evaluation of their career experiences. These aspects of the career decision-making process have been studied in terms of career decision-making self-efficacy (CDMSE; e.g., Taylor \& Betz, 1983), that is, individuals' beliefs regarding their ability to successfully accomplish certain tasks connected with their career choices. However, while some young adults will have more confidence in their ability to manage tasks associated with successful career choices, others will not.

Some studies have suggested that CDMSE depends on time perspective (TP; Epel, Bandura, \& Zimbardo, 1999; Jung, Park, \& Rie, 2015; Walker \& Tracey, 2012). Nonetheless, these studies have

\footnotetext{
' Masaryk University, Brno, Czech Republic

${ }^{2}$ Universidad Peruana de Ciencias Aplicadas, Lima, Peru

Corresponding Author:

Lucia Kvasková, Masaryk University, Brno, Czech Republic.

Email: kvaskova@fss.muni.cz
} 
focused primarily on future TP, since its positive effects on career development have been highly empirically supported. On the other hand, it has been suggested that present and past TPs account for several career decision-making difficulties and predispose individuals to career failure (Taber, 2013; Taber \& Blankemeyer, 2015). However, the associations of future, present, and past TPs with CDMSE have not been fully examined yet, and individuals' low CDMSE and its treatment remain unclear. Thus, the purpose of the present study was to examine the relations between different TPs and CDMSE in young adults.

\section{Career Self-Efficacy}

Bandura (1997) defined self-efficacy as "the belief in one's capabilities to organize and execute courses of action required to produce given attainments" (p. 3). These self-efficacy beliefs influence diverse individual factors such as aspirations and strength of goal commitments, level of motivation and perseverance in the face of difficulties, resilience, and the ability to cope with the demands associated with the chosen course (e.g., Abele \& Spurk, 2009; Prat-Sala \& Redford, 2010; Schwarzer \& Warner, 2013). For this reason, self-efficacy has been examined primarily in connection with academic- and career-related variables. Particularly regarding career self-efficacy, researchers have widely adopted the social cognitive career theory (SCCT; Brown \& Lent, 2016; Lent, 2013; Lent, Brown, \& Hackett, 1994; Lent, Brown, \& Hackett, 2000). This model makes Bandura's (1997) concept of self-efficacy one of the most widely studied variables related to career decision-making. According to the SCCT, personal input (e.g., predispositions such as personality traits) and background contextual factors (e.g., opportunities, resources, barriers, or affordances presented by a particular environment) shape relevant career learning experiences such as performance accomplishments and vicarious learning. In turn, these learning experiences influence career self-efficacy and outcome expectations, which further affect career goals (Brown \& Lent, 2016; Lent, 2013; Lent et al., 1994, 2000).

Some recent studies have examined the SCCT's relevance to the career development of diverse populations within different contexts. Brown and Lent (2017) expressed their hope to stimulate new research that would further expand the theoretical and practical outcomes of the SCCT across diverse individuals, groups, and societies. They specifically referred to Sheu and Bordon's (2017) review of selected research on SCCT's models conducted outside of the United States. The authors suggested important directions to further develop theory and research. First, Sheu and Bordon (2017) noted that only limited attention has been given to person input variables (e.g., personality traits such as Big Five personality traits, perfectionism, and others). Nevertheless, person input variables appear to play a significant role in career self-efficacy (e.g., Andrews, Bullock-Yowell, Dahlen, \& Nicholson, 2014; Bullock-Yowell, Andrews, \& Buzzetta, 2011; Di Fabio \& Saklofske, 2014; Hou, Wu, \& Liu, 2014; Page, Bruch, \& Haase, 2008; Verbruggen \& Sels, 2010). Second, they suggested that to test the generalizability of the SCCT, it needs to be studied also in countries where such research is lacking, such as Eastern European countries, specifically mentioning the Czech Republic.

\section{$T P$}

The individual's construal of the flow of personal experiences into the temporal phases of past, present, or future is called TP. Some authors (Epel et al., 1999; Lewin, 1951) have already suggested that TPs, which are among other cognitive schemas that influence individuals' perspectives, influence one's outcome expectations, motivation, and task-related performance. "Time perspective is the oftennonconscious process whereby the continual flows of personal and social experiences are assigned to temporal categories, or time frames, that help to give order, coherence, and meaning to those events" (Zimbardo \& Boyd, 1999, p. 1271). Thus, TP is a fundamental aspect of an individual's subjective experience. It influences an individual's choices and actions, and it can become a dispositional 
characteristic when an individual's biased TP becomes a dominant way of responding (Boniwell \& Zimbardo, 2004).

In this sense, striving for future goals and rewards, often at the expense of present enjoyment, delayed gratification, and avoidance of time-wasting temptations, determines a future-oriented person's behavior (Boniwell \& Zimbardo, 2004). As such, future-oriented individuals tend to be more successful, both academically and in their careers (Barber, Munz, Bagsby, \& Grawitch, 2009). On the other hand, a past TP would be more focused on family, tradition, and history (Boniwell \& Zimbardo, 2004). Moreover, past TPs can be either positive or negative. A past-positive TP is characterized by a warm and sentimental view of the past that emphasizes maintaining relationships with family and friends (Boniwell \& Zimbardo, 2004). These individuals have the highest sense of self-esteem and happiness compared to those with other dominant TPs (Zimbardo \& Boyd, 1999). In contrast, a past-negative TP reflects a generally negative and aversive view of the past, which may be based on actual negative life experiences or negative reconstruction of past events (Zimbardo \& Boyd, 1999). Zimbardo and Boyd (1999) demonstrated that those scoring high on this factor are not motivated to work for future rewards. Similarly, there are two kinds of present TPs. First, a presenthedonistic TP is oriented toward present enjoyment and excitement with little concern for future consequences. Boniwell and Zimbardo (2004) argued that present hedonists are at risk of academic and career failure. Second, a present-fatalistic TP is associated with hopelessness and belief that the future is predestined; therefore, it is not influenced by individual action. Individuals holding this perspective are unable to see themselves as active agents of their own development and to formulate future goals.

\section{The Link Between Career-Related Self-Efficacy and TP}

Epel, Bandura, and Zimbardo (1999) postulated that both perceived self-efficacy and TP play a fundamental role in motivating behavior. Motivation is determined largely by cognitive representations of future states, that is, by expected outcomes and by cognized future goals (Bandura, 1997). Social cognitive theory points out that goals play a key role in self-regulatory behavior. Furthermore, since career plans, decisions, aspirations, and expressed choices are all essentially goal mechanisms, goals are a ubiquitous, often generally implicit, element of career choice and decision-making theories (Lent et al., 1994). Hence, if individuals do not see the importance of future goals, it is unlikely that they will develop the skills and the necessary self-efficacy to execute the behaviors (e.g., Lent et al., 2008; Zimmerman, 2013). By contrast, striving for future goals and rewards determines futureoriented persons' behavior, and this future TP has been found to be positively related to CDMSE among undergraduate students (Jung et al., 2015; Walker \& Tracey, 2012).

While no study has investigated the role of TPs other than the future one in CDMSE, some research has suggested that present and past TPs may also influence career development (e.g., Taber, 2013; Taber \& Blankemeyer, 2015). More concretely, Taber (2013) examined the relationship between the multidimensional nature of TP and adults' career decision-making difficulties. The results of his study indicated that the negative valences of past-negative and present-fatalistic TP, coupled with presenthedonistic TP, accounted for several career decision-making difficulties. The results further showed that those high in future and low in present-fatalism TPs experienced fewer problems regarding lack of motivation and indecisiveness. Furthermore, Taber and Blankemeyer (2015) examined multivariate relations between vocational identity statuses and TPs in emerging adults. They found that diffuse vocational identity status is associated with negative views of the past and lower orientation toward the future and that achieved vocational identity is associated with a largely hedonic view of the present, increased mindfulness, and decreased fatalistic attitudes. Coupled with the results of the studies examining self-efficacy in connection with TP, it seems that the three TPs (i.e., future, past-negative, and present-fatalistic, TPs) show a consistent pattern of the relationship between TP and career variables. 
Drawing from these results, it seems that while future TP might play a positive role in enhancing CDMSE, present TPs together with past-negative TP contribute to low self-efficacy. The negative role of past-negative TP might reside in the lack of social support. Individuals with past-negative TP reported less involvement with family (Goldberg \& Maslach, 1996), fewer parental figures and other relatives in one's network, lower levels of social support, and higher levels of social conflict, especially with family members (Holman \& Zimbardo, 2009). Another study has shown that people with past-negative TP reported having fewer close friends and considered their interpersonal relationships to be minimal and unsatisfactory (Zimbardo \& Boyd, 1999). In this line of research, many studies have already indicated that the quality of interpersonal relationships plays a key role in building selfefficacy (e.g., Wentzel, Muenks, McNeish, \& Russell, 2017; Zhang \& Huang, 2018). Thus, we assume that people who are past-negatively oriented might have difficulties building strong CDMSE because they lack quality social support.

Apart from past-negative TP, present TPs were found to have a negative connection with successful career development (Epel et al., 1999). Epel et al. (1999) argued that those who distrust their ability to influence the course of events have little incentive to look to the future to set distant goals for themselves. They are more likely to adopt a fatalistic present-oriented perspective in their everyday lives. Thus, they hypothesized that a low present orientation would accompany a high sense of personal efficacy. Their results indeed showed a negative correlation between present orientation and perceived general self-efficacy.

Derived from these studies, we hypothesized that future TP will be positively related to CDMSE, past-negative TP will be negatively related to CDMSE, and present-fatalistic TP will be negatively related to CDMSE.

\section{Present Study}

Our study targeted young people living in the Czech Republic. In general, we can assume that the living conditions and lifestyle of young Czechs do not differ much from their peers in Western and Central Europe (Arnett, 2006; Macek, Bejček, \& Vaníčková, 2007). The time of study and career preparation of young Czechs has expanded, as about $60 \%$ of Czechs are still undertaking some formal studies at ages 18-24 (Czech Statistical Office, 2014), and each year, the number of college students increases. It should be noted that public university education is free of charge in the Czech Republic. Moreover, many young people aged 20-25 are still economically dependent on their primary families, and about half of them still live with their parents. Thus, Czech young people usually achieve other milestones of adulthood by considering their school and/or career progress. Marriage, independent household, parenthood, and home ownership may all be dependent upon finishing school or getting a stable job (Katrňák, Lechenrová, Pakosta, \& Fučík, 2010). This, however, is less true today than in the past, as the numbers of unemployed or underemployed individuals with university degrees are rising (Czech Employment Office, 2014).

To understand the lives of the present-day Czech emerging adults, we must consider the social changes that have occurred over the past several decades, both in former Czechoslovakia and in the current Czech Republic, which have greatly affected this generation and the generation of their parents. The present generation of young Czechs has different life experiences compared to the previous generations, including their parents' generation. The present Czech emerging adults were born in the 1980 s, that is, during the totalitarian communist regime that was marked by great dependence on the authority of the state, which was associated with a low degree of personal freedom and freedom to express one's own ideas. As opposed to the previous period, most emerging adults have freedom of choice when making decisions about their own lives, and their parents often encourage them to take opportunities they did not have when they were young. However, the effect of the so-called postcommunist syndrome, characterized by low self-confidence, avoidance of initiative and responsibility, 
hopelessness, and pessimism, persists in the society (Klicperová, Feierabend, \& Hofstetter, 1997; Macek \& Marková, 2004). Such characteristics resemble the ones associated with the presentfatalistic TP, and they might impede building strong CDMSE, making the career decision-making process more difficult for young people.

\section{Method}

\section{Participants and Procedure}

The data were collected in the Czech Republic. The participants were taking part in the longitudinal project Pathways to Adulthood. The main purpose of the project was to examine the ways in which young people develop their autonomy and identity associated with their personal relationships, education, and work. In this project, universities, secondary schools, companies, and employment offices in the Czech Republic were randomly selected and asked to participate in the project ( $26 \%$ of the participants were recruited in this way). Additionally, $16 \%$ of respondents were recruited in person (e.g., instructors announced our project in their classes). Finally, the project was also advertised on the Facebook event page, the faculty website, newspapers, and local TV broadcasting ( $58 \%$ of the participants were recruited in this way). The questionnaires were e-mailed to the participants who then responded to them online. The data on different relevant topics were collected at three time points over 1 year. Some of the participants who responded to all three waves of our study were selected by a lottery to receive a small gift (a T-shirt, a backpack, and among others) as an incentive for their participation.

Overall, this longitudinal study gathered data at six time points. Being an open survey, some participants provided information at all time points, whereas others only provided information at one time point. In the present study, inclusion criteria included being a student and providing information on both predictor variables (TP) and outcome variable (CDMSE) at least at one of the two time points at which it was assessed. Specifically, the data to be analyzed came from the third, fifth, and sixth time points, further referred to as Time 0 (December 2014, data on TP, our main predictor variable), Time 1 (December 2015, first data collection on our outcome variable, CDMSE), and Time 2 (July 2016, second data collection on our outcome variable), respectively. Thus, 492 met the inclusion criteria out of 1,753 participants included in the whole longitudinal study. Sociodemographic information of participants was collected at the first, second, and fourth time points.

Due to the repeated measures, there were no missing data on variables like gender, age, and education. Given the inclusion criteria outlined above, all participants in the final sample $(N=492)$ provided data on TP. Although the majority $(69.3 \%, n=341)$ provided data on CDMSE at both time points, $16.1 \%(n=79)$ provided data on CDMSE at Time 1 but not at Time 2 , and $14.6 \%(n=72)$ at Time 2 but not at Time 1. Finally, 29 cases (5.89\%) had missing data on socioeconomic status (SES). Therefore, to deal with missing data in our main analyses (see below), we employed the maximum likelihood estimation method, which uses all available information for each variable and its standard errors to estimate the parameters of the statistical model (e.g., Goldstein, 2011).

Compared with nonselected participants $(N=1,261, M=22.93$ years, $S D=1.60$, range $=18.3-$ 30.3), selected participants $(n=492, M=22.97$ years, $S D=1.32$, range $=18-28.5)$ did not differ in age, $t=-0.49(d f=1,076), p=.621, M_{\text {dif }}=-0.37$ years, $95 \%$ confidence interval $(\mathrm{CI})=[-0.18$, $0.11]$. Moreover, selected participants were more likely to be women $(n=408,82.9 \%)$, compared to nonselected participants $(n=898,72.1 \%), \chi^{2}(1,1,737)=22.04, p<.001$. They also had a higher educational attainment $(n=200,40.7 \%$ with higher education, $n=290,58.9 \%$ with secondary education, and $n=2,0.4 \%$ with primary education) compared to nonselected participants ( $n=165,13.3 \%$ with higher education, $n=906,73.3 \%$ with secondary education, and $n=165,13.3 \%$ with primary education), $\chi^{2}(2,1,728)=195.66, p<.001$. Similarly, they had a slightly higher SES $(M=23.78$, 
$S D=5.63)$ compared to nonselected participants $(M=22.50, S D=5.70), t=-4.11(d f=1,596)$, $p=.001, M_{\text {dif }}=-1.29,95 \%$ CI $[-1.90,-0.67]$.

\section{Measures}

Sociodemographic data. Participants were asked to provide information about their occupation $(1=$ studying, $2=$ working, $3=$ studying and working, and $4=$ unemployed). For this study, only participants who reported "studying" or "studying and working" were included. To calculate their SES, participants were asked to report the occupation of their mother and father as well as their parents' income (from $1=$ very poor to $10=$ very rich) and educational attainment (from $1=$ elementary school to $10=$ doctoral degree). The responses to these three questions were summed up to obtain a composite score. Finally, the participants' educational attainment (from $1=$ elementary school to $9=$ master's degree $)$ was recoded into a three-level categorical variable $(1=$ primary education, $2=$ secondary education, and $3=$ tertiary education). However, this variable was then recoded into a binary variable for the main analyses $(0=$ secondary education, $1=$ higher education $)$, and the only two participants with primary education were included in the "secondary education" category.

TP. The Zimbardo Time Perspective Inventory (ZTPI; Zimbardo \& Boyd, 1999; Czech version: Lukavská, Klicperová-Baker, Lukavský, \& Zimbardo, 2011) was used to measure participants' TPs. The ZTPI is a 56-item inventory with 5 subscales reflecting the temporal zones of past-positive (9 items, e.g., "I get nostalgic about my childhood"), past-negative (10 items, e.g., "I often think about what I should have done differently in my life"), present-hedonistic (15 items, e.g., "I make decisions on the spur of the moment"), present-fatalistic (9 items, e.g., "You can't really plan for the future because things change so much"), and future (13 items, e.g., "Before making a decision, I weight the costs against the benefits") TPs. The responses were measured on a Likert-type scale ranging from 1 (strongly disagree) to 5 (strongly agree). Scores for each subscale were computed by averaging the 9 past-positive, 10 past-negative, 15 present-hedonistic, 9 present-fatalistic, and 13 future orientation items. The psychometric properties of five-scale ZTPI proved to be good (Lukavská et al., 2011). In our study, the internal consistency of the scales ranged from $\alpha=.73$ to $\alpha=.82$.

CDMSE. Emerging adults' self-efficacy in their ability to select career goals and their ability to search for occupational information was assessed using the Career Decision-Making Self-Efficacy Short Form (CDMSE-SF; Betz, Klein, \& Taylor, 1996). The subscales of the CDMSE-SF include SelfAppraisal (e.g., "I can determine what my ideal job would be"), Gathering Occupational Information (e.g., "Talk with a person already employed in a field you are interested in"), Goal Selection (e.g., "Choose a major or career that will fit your interests"), Making Plans (e.g., "I can prepare a good resume"), and Problem-Solving (e.g., "I can change careers if I did not like my first choice"). The responses were measured on a 5-point Likert-type scale ranging from 0 (no confidence) to 5 (complete confidence). A total score reflecting CDMSE was computed by summing the confidence ratings for all 25 items. In accordance with the suggestion of some authors (e.g., Geisinger, 1994), a researcher who is skilled in target languages and familiar with this construct translated the questionnaire items. Subsequently, other research team members who met the same criteria carefully reviewed the quality of the translation and decided on a final translated version. Items were translated into the Czech language without any substantial changes. Previous studies have supported the convergent validity of the subscales with other measures of adaptive career development (Betz, Hammond, \& Multon, 2005). We conducted a confirmatory factor analysis using structural equation modeling to test the unidimensional validity of our translated version. Weighted least squares mean and variance adjusted, which uses the diagonally weighted least squares technique, was used as an estimation method. To perform these analyses, we used the package lavaan Version 0.6-3 (Rosseel et al., 2018) in R Version 3.5.2. 
Table I. Means, Standard Deviations, and Correlations Between Continuous Variables Across Time I and Time 2.

\begin{tabular}{|c|c|c|c|c|c|c|c|c|c|c|}
\hline & Time I & Time 2 & & & & & & & & \\
\hline Variables & $M(S D)$ & $M(S D)$ & I & 2 & 3 & 4 & 5 & 6 & 7 & 8 \\
\hline I. Age & $22.94(I .3 I)$ & $22.99(1.30)$ & - & .01 & .08 & .01 & -.03 & -.07 & -.09 & .08 \\
\hline 2. SES & $23.77(5.64)$ & $23.99(5.65)$ & $.14 * *$ & - & $.11 *$ & -.04 & $-.21 * *$ & .06 & -.09 & .05 \\
\hline 3. ZTP-I-FO & $3.55(0.58)$ & $3.58(0.57)$ & .07 & $.12 *$ & - & $-.36 * *$ & $-.22 * *$ & .07 & -.02 & $.29 * *$ \\
\hline 4. ZTP-I-PH & $3.17(0.54)$ & $3.15(0.53)$ & -.03 & -.08 & $-.35^{* *}$ & - & $.31 * *$ & .09 & -.02 & -.04 \\
\hline 5. ZTP-I—PF & $2.42(0.59)$ & $2.4 I(0.59)$ & -.01 & $-.21^{* *}$ & $-.24 * *$ & $.31 * *$ & - & $.22^{* *}$ & $.42 * *$ & $-.33 * *$ \\
\hline 6. ZTP-I-PP & $3.34(0.59)$ & $3.36(0.57)$ & -.07 & .03 & .06 & .08 & $.15^{* *}$ & - & $.12 *$ & -.05 \\
\hline 7. ZTP-I—PN & $2.97(0.72)$ & $2.92(0.69)$ & -.09 & $-.13^{*}$ & -.02 & -.01 & $.40 * *$ & $.11 *$ & - & $-.30 * *$ \\
\hline 8. CDMSE & $3.82(0.62)$ & $3.88(0.61)$ & $.11 *$ & 0.04 & $.29 * *$ & .03 & $-.30 * *$ & -.08 & $-.27 * *$ & - \\
\hline
\end{tabular}

Note. $N=492$. Correlations above the diagonal are for Time I $(n=420)$, and those below the diagonal are for Time $2(n=4 I 3)$. SES = socioeconomic status; ZTP-I—PN = Past-Negative subscale; ZTP-I—PP = Past Positive subscale; ZTP-I—PF = PresentFatalistic subscale; ZTP-I-PH = Present-Hedonistic subscale; ZTP-I-FO = Future Orientation subscale; CDMSE $=$ career decision-making self-efficacy.

$* p<.05 . * * p .01$.

With 444 cases providing data on CDMSE at the first time point, we obtained good fit indices, $\chi^{2}=$ $1,424.04(d f=275), p<.001$, comparative fit index $(\mathrm{CFI})=.973$, root mean square error of approximation $(\mathrm{RMSEA})=.097,95 \% \mathrm{CI}[0.092,0.102]$, standardized root mean square residual $(\mathrm{SRMR})=$ .079 , and standardized loadings from 0.46 to 0.81 .

With 425 cases providing data on CDMSE at the second time point, we obtained acceptable fit indices, $\chi^{2}=1,371.44(d f=275), p<.001, \mathrm{CFI}=.972$, RMSEA $=.097,95 \%$ CI $[0.092,0.102]$, $\mathrm{SRMR}=.080$, and all item standardized loadings above .5 (from 0.55 to 0.78 ). The internal consistencies at Time 1 and Time 2 in our study were both $\alpha=.94$.

The main data analyses were performed in IBM SPSS Version 25. Multilevel modeling was chosen due to several advantages over traditional analyses (e.g., standard regression). Multilevel modeling allows handling missing data (see above), while respecting the clustered structure of the data, which allows better estimates of regression coefficients, correct standard errors, CIs, and significance tests (see Goldstein, 2011). All TPs were included as fixed predictors in these analyses, whereas education $(0=$ secondary education, $1=$ higher education $)$, gender $(0=$ female, $1=$ male $)$, age $($ range $=$ 18-28.5 years), and SES (range from 8 to 34) were included as fixed covariates. As random effects, other than the intercept, we included all cross-level interactions between time and each TP.

\section{Results}

\section{Demographic Characteristics of the Sample}

The means (with $S D$ s) of the study variables and their correlation coefficients are presented in Table 1 . Correlations at Time 2 are displayed on the left side of the table under the diagonal and correlations at Time 1 are displayed on the right side of the table above the diagonal.

Regarding correlations of CDMSE with TP, they were very similar in both time points. The correlations of CDMSE with past-positive and present-hedonistic perspectives were nonsignificant (Table 1). 
Table 2. Estimated Parameters of Multilevel Regression Predicting Career Decision-Making Self-Efficacy (CDMSE).

\begin{tabular}{|c|c|c|c|}
\hline \multirow[b]{2}{*}{ Parameter } & \multicolumn{3}{|c|}{ CDMSE } \\
\hline & Coefficient & SE & $p$ \\
\hline Intercept & 3.57 & .56 & $<.01$ \\
\hline Time & -0.03 & .26 & .90 \\
\hline Education & 0.09 & .07 & .19 \\
\hline Sex & 0.01 & .06 & .80 \\
\hline Age & -0.01 & .02 & .52 \\
\hline Socioeconomic status & -0.00 & .00 & .48 \\
\hline ZTP-I-FO & 0.33 & .05 & $<.01$ \\
\hline ZTP-I-PH & 0.15 & .06 & .01 \\
\hline ZTP-I-PF & -0.24 & .05 & $<.001$ \\
\hline TP-I-PP & 0.01 & .05 & .87 \\
\hline ZTP-I-PN & -0.17 & .04 & $<.01$ \\
\hline Time $\times$ ZTP-I - FO & 0.02 & .04 & .58 \\
\hline Time $\times$ ZTP-I - PH & 0.06 & .04 & .15 \\
\hline Time $\times$ ZTP-I - PF & 0.01 & .04 & .85 \\
\hline Time $\times$ ZTP-I - PP & -0.10 & .04 & .01 \\
\hline \multirow[t]{2}{*}{ Time $\times$ ZTP-I - PN } & 0.04 & .03 & .20 \\
\hline & Model & & Significance \\
\hline Residual variance & 0.07 & & .006 \\
\hline \multicolumn{4}{|l|}{ Information criteria } \\
\hline log-likelihood multiplied by negative two & $1,087.93$ & & \\
\hline AIC & $\mathrm{I}, 123.93$ & & \\
\hline $\mathrm{BIC}$ & $\mathrm{I}, 208.77$ & & \\
\hline Parameters & 18 & & \\
\hline
\end{tabular}

Note. Time point $(0=$ Time $I, I=$ Time 2$)$, education $(0=$ secondary education, $\mathrm{I}=$ higher education $)$, sex $(0=$ female, $\mathrm{I}=$ male), age (range $=18-28.5$ years), and socioeconomic status (range from 8 to 34). Boldface estimates are statistically significant. Estimate coefficients and standard errors are given with three digits to ease interpretation. ZTP-I-PN $=$ Past-Negative subscale; ZTP-I—PP = Past-Positive subscale; ZTP-I—PF = Present-Fatalistic subscale; ZTP-I-PH = Present-Hedonistic subscale; ZTP-I-FO = Future Orientation subscale; AIC = Akaike information criterion; $\mathrm{BIC}=$ Bayesian information criterion.

\section{Association Between TP and Career Decision-Making Self-Efficacy}

To further understand the associations between variables, a multilevel regression analysis was performed. Parameters of these models are shown in Table 2. Gender, age, education, and SES were introduced as covariates, and all Zimbardo TPs were included, as well as their interaction with time. The results of these analyses showed that past-negative, $b=-.17, t(615.56)=-4.01, p<.001$; future, $b=.33, t(625.12)=6.55, p<.001$; present-hedonistic, $b=.15, t(624.38)=2.79, p=.01$; and present-fatalistic TP, $b=-.24, t(636.66)=-4.40, p<.001$, were significant predictors of CDMSE. Interactions in the model showed that the interaction between time point (as a variable of time) with past-positive TP was significant, $b=-.10, t(370.50)=-2.73, p=.01$.

\section{Discussion}

The aim of our research was to explore the relationship between TPs and CDMSE. In line with previous research, the findings of our study supported our first hypothesis, which proposed that future TP will be positively related to CDMSE in young adults. More concretely, our results supported the previous findings that future TP is associated with greater CDMSE (Jung et al., 2015; Walker \& Tracey, 2012). 
Besides the positive role of future TP in CDMSE, we were investigating the negative role of present and past TPs in CDMSE. In this way, the results of our study also supported the hypothesis proposing that past-negative TP will be negatively related to CDMSE. Although CDMSE has not been studied in connection with past-negative TP, some studies pointed out that past-negative TP contributes to negative markers of career identity such as career decision-making difficulties (Taber, 2013) and diffuse vocational identity (Taber \& Blankemeyer, 2015). Previous research has shown that past-negative TP is related to less involvement with family (Goldberg \& Maslach, 1996) and higher conflict with family members (Holman \& Zimbardo, 2009), as well as with minimal and unsatisfactory interpersonal relationships (Zimbardo \& Boyd, 1999). Given that the quality of interpersonal relationships is essential for building self-efficacy (e.g., Wentzel et al., 2017; Zhang \& Huang, 2018), we suggest that people who lack quality social support might have difficulty in successfully progressing on a career path.

The results of our study also supported the hypothesis that present-fatalistic TP will be negatively related to CDMSE. Even though CDMSE has not been studied in connection with present-fatalistic TP, some studies have shown that it has some negative effect on career identity variables (e.g., Taber, 2013; Taber \& Blankemeyer, 2015). Individuals with present-fatalistic views distrust their ability to influence the course of events, and as such, they have little incentive to look to the future to set goals for themselves (Zimbardo \& Boyd, 1999). Since higher scores on the scale of CDMSE represent also greater confidence in setting clear career goals, it seems logical that those who are oriented toward present-fatalistic TP would score lower on CDMSE. Moreover, present-fatalistic TP has been found to correlate positively with depression and anxiety (Zimbardo \& Boyd, 1999), which are both negatively connected to self-efficacy (e.g., Flett, Panico, \& Hewitt, 2011).

We found one unexpected significant and positive association between present-hedonistic TP and CDMSE. The role of the present-hedonistic TP in career development is not clear. For example, while Taber (2013) showed that present-hedonistic TP contributes to several career decisionmaking difficulties, Taber and Blankemeyer (2015) showed that present-hedonistic TP is associated with achieved vocational identity. Additionally, Holman and Zimbardo (2009) found that respondents who were high on present hedonism reported higher levels of social companionship and more support from friends and acquaintances. We already mentioned the importance of social support in CDMSE (e.g., Huafeng \& Haitao, 2018; Wentzel et al., 2017). Thus, it seems that those adolescents who tend to enjoy immediate life's pleasures form larger social networks and benefit from social support in the career domain as well.

However, it is important to consider an interplay between particular TP dimensions. Zimbardo and Boyd (2008) already emphasized that excessive development of any TP increases the risk of numerous threats (e.g., addictions in present hedonists and workaholic tendencies in future-oriented individuals) if it is not counterbalanced with an appropriate level of another TP. As such, the ability to flexibly switch between present-hedonistic and future TP can enhance individuals' well-being (Stolarski, Matthews, Postek, Zimbardo, \& Bitner, 2013; Stolarski, Wiberg, \& Osin, 2015). Thus, it seems that when present-hedonistic TP is balanced with future-oriented TP, present-hedonistic TP can contribute to CDMSE and also to other variables that are related to progress in career decision-making.

\section{Implication for Practice}

Research clearly shows that CDMSE plays an important role in career decision-making, performance, and persistence (e.g., Restubog, Florentino, \& Garcia, 2010; Wright, Jenkins-Guarnieri, \& Murdock, 2013). Thus, because significant relations were found between the CDMSE and TP, interventions that focus specifically on TP may be useful in facilitating CDMSE. First, career counselors should orient clients toward the future, so that they can explore their career possibilities, set their career goals, and act to fulfill these goals. Taber (2015), for example, described such intervention for adolescents and 
emerging adults, suggesting a concrete way to reflect on the client's temporal zones by reinforcing positive statements about the future and optimistic attitudes toward it.

However, some people opt to focus on the present or the past instead of the future. In our study, present-fatalistic and past-negative TPs were negatively associated with CDMSE. In many cases, individuals' negative conceptions of the past and the present prevent them from engaging in activities that could enhance CDMSE and subsequently successful career transitions (e.g., Brown \& Lent, 2017; Lent, 2013). In such cases, Taber (2015) proposed to focus on how past errors, regrets, or circumstances can be avoided in the future to provide the motivational push for actively working to achieve future goals. Furthermore, the counselor may facilitate the client's learning experience. Gaining a positive experience is indeed important, since performance accomplishment has been found to be the most powerful intervention in increasing self-efficacy (Betz, 2004). Thus, helping clients reinterpret their present/past-negative experiences, orient them toward future goals, and help them achieve a positive performance accomplishment are all important in building CDMSE.

\section{Study Limitations}

The current study has some limitations. First, the nature of the study is correlational; thus, no causeand-effect statements can be made. Although the theoretical conceptualization suggests that TP as a personal input shapes relevant career learning experiences and thus self-efficacy, future research should verify this pattern by using longitudinal research design.

Second, the participants in our study consisted mostly of female university students from the Czech Republic, so the selected sample limits the generalizability of the findings. Previous research (e.g., Andretta, Worrell, Mello, Dixson, \& Baik, 2013; Betz et al., 1996; Ely \& Mercurio, 2011; Mello \& Worrell, 2006; Sircova et al., 2007; Zimbardo \& Boyd, 1999) has revealed gender differences in self-efficacy and TPs. Some studies proposed that women score higher on future TP and past-positive TP compared to men (e.g., Zimbardo \& Boyd, 1999). However, those gender differences were not observed in other studies (Greene \& DeBacker, 2004). Such inconsistent results could be due to differences in academic achievement. In particular, gender differences in TP may be less pronounced among academically talented youth as opposed to the general academic population. Prior research (Honora, 2002) has shown that gender interacts with academic achievement in predicting TP variables.

Some cross-cultural differences in TP and in self-efficacy have been found (e.g., Andretta et al., 2013; Scholz, Doña, Sud, \& Schwarzer, 2002). In the Czech Republic, a postcommunist syndrome characterized by low self-confidence, avoidance of initiative and responsibility, hopelessness, and pessimism is still present (Klicperová et al., 1997; Macek \& Marková, 2004). Such characteristics might reflect higher scores on the fatalistic perspective and also lower scores on self-efficacy. Thus, future research on TPs and career self-efficacy should incorporate more diverse and noncollege participants to verify the results.

\section{Conclusion}

The present study is the first to examine the role of various TPs in the CDMSE in emerging adults. Our results revealed that future TP and present-hedonistic TP are positively related to CDMSE. Moreover, CDMSE was negatively associated with present-fatalistic TP and past-negative TP. These findings draw attention to the fact that in addition to the most commonly studied future TP, other TPs also play a key role in CDMSE and most likely in other career and academic variables. Future studies should also examine a balanced TP. 


\section{Declaration of Conflicting Interests}

The author(s) declared no potential conflicts of interest with respect to the research, authorship, and/or publication of this article.

\section{Funding}

The author(s) declared the following potential conflicts of interest with respect to the research, authorship, and/or publication of this article: DOMOV, CESTY, PARTICIPACE: 2019 (MUNI/A/1138/ 2018).

\section{References}

Abele, A. E., \& Spurk, D. (2009). The longitudinal impact of self-efficacy and career goals on objective and subjective career success. Journal of Vocational Behavior, 74, 53-62. doi:10.1016/j.jvb.2008.10.005

Andretta, J. R., Worrell, F. C., Mello, Z. R., Dixson, D. D., \& Baik, S. H. (2013). Demographic group differences in adolescents' time attitudes. Journal of Adolescence, 36, 289-301. doi:10.1016/j.adolescence.2012.11.005

Andrews, L. M., Bullock-Yowell, E., Dahlen, E. R., \& Nicholson, B. C. (2014). Can perfectionism affect career development? Exploring career thoughts and self-efficacy. Journal of Counseling and Development, 92, 270-279. doi:10.1002/j.1556-6676.2014.00155.x

Arnett, J. J. (2006). Emerging adulthood in Europe: A response to Bynner. Journal of Youth Studies, 9, 111-123. doi:10.1080/13676260500523671

Arnett, J. J. (2014). Adolescence and emerging adulthood: A cultural approach. Upper Saddle River, NJ: Pearson Prentice Hall.

Bandura, A. (1997). Self-efficacy: The exercise of control. New York, NY: W. H. Freeman.

Barber, L. K., Munz, D. C., Bagsby, P. G., \& Grawitch, M. J. (2009). When does time perspective matter? Selfcontrol as a moderator between time perspective and academic achievement. Personality and Individual Differences, 46, 250-253. doi:10.1016/j.paid.2008.10.007

Betz, N. E. (2004). Contributions of self-efficacy theory to career counseling: A personal perspective. Career Development Quarterly, 52, 340-353. doi:10.1002/j.2161-0045.2004.tb00950.x

Betz, N. E., Hammond, M., \& Multon, K. (2005). Reliability and validity of five-level response continua for the Career Decision Self-Efficacy Scale. Journal of Career Assessment, 13, 131-149. doi:10.1177/ 1069072704273123

Betz, N. E., Klein, K., \& Taylor, K. (1996). Evaluation of a short form of the career decision-making self-efficacy scale. Journal of Career Assessment, 4, 47-57. doi:10.1177/106907279600400103

Boniwell, I., \& Zimbardo, P. (2004). Balancing time perspective in pursuit of optimal functioning. In P. A. Linley \& S. Joseph (Eds.), Positive psychology in practice (pp. 165-178). New Jersey, NJ: John Wiley.

Brown, S. D., \& Lent, R. W. (2016). Vocational psychology: Agency, equity, and well-being. Annual Review of Psychology, 67, 541-565. doi:10.1146/annurev-psych-122414-033237

Brown, S. D., \& Lent, R. W. (2017). Social cognitive career theory in a diverse word: Closing thoughts. Journal of Career Assessment, 25, 173-180. doi:10.1177/1069072716660061

Bullock-Yowell, E., Andrews, L., \& Buzzetta, M. (2011). Explaining career decision-making self-efficacy: Personality, cognitions, and cultural mistrust. The Career Development Quarterly, 59, 400-411. doi:10.1002/j. 2161-0045.2011.tb00967.x

Czech Employment OfficeUPCR. (2014). Registered unemployment rate from 1997 to 2012 [Data file]. Retrieved from http://portal.mpsv.cz/sz/stat/nz/casove_rady

Czech Statistical Office. (2014). Vybrané demografické údaje v České republice. Praha, Czech Republic: Český statistický úrad [Demographic data on Czech Republic. Prague: Czech Statistical Office]. Retrieved from https://www.czso.cz/documents/ 
Di Fabio, A., \& Saklofske, D. H. (2014). Comparing ability and self-report trait emotional intelligence, fluid intelligence, and personality traits in career decision. Personality and Individual Differences, 64, 174-178. doi:10. 1016/j.paid.2014.02.024

Ely, R., \& Mercurio, A. (2011). Time perspective and autobiographical memory: Individual and gender differences in experiencing time and remembering the past. Time \& Society, 20, 375-400. doi:10.1177/ $0961463 X 10366081$

Epel, E. S., Bandura, A., \& Zimbardo, P. G. (1999). Escaping homelessness: The influences of self-efficacy and time perspective on coping with homelessness. Journal of Applied Social Psychology, 29, 575-596. doi:10. 1111/j.1559-1816.1999.tb01402.x

Flett, G. L., Panico, T., \& Hewitt, P. L. (2011). Perfectionism, type A behavior, and self-efficacy in depression and health symptoms among adolescents. Current Psychology, 30, 105-116. doi:10.1007/s12144-011-9103-4

Geisinger, K. F. (1994). Cross-cultural normative assessment: Translation and adaptation issues influencing the normative interpretation of assessment instruments. Psychological Assessment, 6, 304-312. doi:10.1037/ 1040-3590.6.4.304

Goldberg, J., \& Maslach, C. (1996). Understanding time: Connections between the past and future. Paper presented at the annual convention of the Western Psychological Association, San Jose, CA.

Goldstein, H. (2011). Multilevel statistical models (4th ed.). Chichester, England: Wiley.

Greene, B. A., \& DeBacker, T. K. (2004). Gender and orientations toward the future: Links to motivation. Educational Psychology Review, 16, 91-120. doi:10.1023/B:EDPR.000026608.50611.b4

Holman, E. A., \& Zimbardo, P. G. (2009). The social language of time: The time perspective-social network connection. Basic and Applied Social Psychology, 31, 136-147. doi:10.1080/01973530902880415

Honora, D. T. (2002). The relationship of gender and achievement to future outlook among African American adolescents. Adolescence, 37, 301-316.

Hou, C., Wu, L., \& Liu, Z. (2014). Effect of proactive personality and decision-making self-efficacy on career adaptability among Chinese graduates. Social Behavior and Personality: An International Journal, 42, 903-912. doi:10.2224/sbp.2014.42.6.903

Huafeng, Z., \& Haitao, H. (2018). Decision-making self-efficacy mediates the peer support-career exploration relationship. Social Behavior \& Personality: An International Journal, 46, 485-498. doi:10.2224/sbp.6410

Jung, H., Park, I.-J., \& Rie, J. (2015). Future time perspective and career decisions: The moderating effects of affect spin. Journal of Vocational Behavior, 89, 46-55. doi:10.1016/j.jvb.2015.04.010

Katrňák, T., Lechenrová, Z., Pakosta, P., \& Fučík, P. (2010). Na prahu dospelosti: Partnerstvi', sex a zǐvotni prèdstavy mladých v současné céské společnosti [At the doorsteps of adulthood: Relationships, sex and life plans of youth in current Czech society]. Prague, Czech Republic: Dokořán.

Klicperová, M., Feierabend, I. K., \& Hofstetter, C. R. (1997). In the search for a postcommunist syndrome: A theoretical framework and empirical assessment. Journal of Community \& Applied Social Psychology, 7, 39-52. doi:10.1002/(SICI)1099-1298(199702)7:13.0.CO;2-1

Lent, R. W. (2013). Social cognitive career theory. In S. D. Brown \& R. W. Lent (Eds.), Career development and counseling: Putting theory and research to work (pp. 115-146, 2nd ed.). Hoboken, NJ: Wiley.

Lent, R. W., Brown, S. D., \& Hackett, G. (1994). Toward a unifying social cognitive theory of career and academic interest, choice, and performance. Journal of Vocational Behavior, 45, 79-122. doi:10.1006/jvbe. 1994.1027

Lent, R. W., Brown, S. D., \& Hackett, G. (2000). Contextual supports and barriers to career choice: A social cognitive analysis. Journal of Counseling Psychology, 47, 36-49. doi:10.1037/0022-0167.47.1.36

Lent, R. W., Sheu, H. B., Singley, D., Schmidt, J. A., Schmidt, L. C., \& Gloster, C. S. (2008). Longitudinal relations of self-efficacy to outcome expectations, interests, and major choice goals in engineering students. Journal of Vocational Behavior, 73, 328-335. doi:10.1016/j.jvb.2008.07.005

Lewin, K. (1951). Field theory in social science. New York, NY: Harper \& Brothers. 
Lukavská, K., Klicperová-Baker, M., Lukavský, J., \& Zimbardo, P. G. (2011). ZTPI - Zimbardův dotazník časové perspektivy [ZTPI - Zimbrado Time Perspective Inventory - Czech validization study]. Čskoslovenská psychologie, 4, 357-375.

Macek, P., Bejček, J., \& Vaníčková, J. (2007). Contemporary Czech emerging adults: Generation growing up in the period of social changes. Journal of Adolescent Research, 22, 444-475. doi:10.1177/0743558407305417

Macek, P., \& Marková, I. (2004). Trust and distrust in old and new democracies. In I. Marková (Ed.), Trust and democratic transition in post-communist Europe (pp. 173-194). New York, NY: Oxford University Press.

Mello, Z. R., \& Worrell, F. C. (2006). The relationship of time perspective to age, gender, and academic achievement among academically talented adolescents. Journal for the Education of the Gifted, 29, 271-289. doi:10. $1177 / 016235320602900302$

Page, J., Bruch, M. A., \& Haase, R. F. (2008). Role of perfectionism and five-factor model traits in career indecision. Personality and Individual Differences, 45, 811-815. doi:10.1016/j.paid.2008.08.013

Prat-Sala, M., \& Redford, P. (2010). The interplay between motivation, self-efficacy and approaches to studying. British Journal of Educational Psychology, 80, 283-305. doi:10.1348/000709909X480563

Restubog, S. L. D., Florentino, A. R., \& Garcia, P. R. J. M. (2010). The mediating roles of career self-efficacy and career decidedness in the relationship between contextual support and persistence. Journal of Vocational Behavior, 77, 186-195. doi:10.1016/j.jvb.2010.06.005

Rosseel, Y., Oberski, D., Byrnes, J., Vanbrabant, L., Savalei, V., Merkle, E., ... Jorgensen, T. D. (2018). Package 'lavaan.' Retrieved from https://file://D:/426873/Downloads/lavaan.pdf

Scholz, U., Doña, B. G., Sud, S., \& Schwarzer, R. (2002). Is general self-efficacy a universal construct? Psychometric findings from 25 countries. European Journal of Psychological Assessment, 18, 242-251. doi:10.1027/ 1015-5759.18.3.242

Schwarzer, R., \& Warner, L. M. (2013). Perceived self-efficacy and its relationship to resilience. In A. Prince Embury \& D. H. Saklofske (Eds.), Resilience in children, adolescents, and adults: Translating research into practice (pp. 139-150). New York, NY: Springer.

Sheu, H. B., \& Bordon, J. J. (2017). SCCT research in the international context: Empirical evidence, future directions, and practical implications. Journal of Career Assessment, 25, 58-74. doi:10.1177/1069072716657826

Sircova, A., Mitina, O. V., Boyd, J., Davydova, I. S., Zimbardo, P. G., Nepryaho, T. L., ... Yasnaya, V. A. (2007). The phenomenon of time perspective across different cultures: Review of researches using ZPTI scale. Cultural-Historical Psychology, 4, 19-31.

Stolarski, M., Matthews, G., Postek, S., Zimbardo, P. G., \& Bitner, J. (2013). How we feel is a matter of time: Relationships between time perspectives and mood. Journal of Happiness Studies, 15, 809-827. doi:10. 1007/s10902-013-9450-y

Stolarski, M., Wiberg, B., \& Osin, E. (2015). Assessing temporal harmony: The issue of a balanced time perspective. In M. Stolarski, N. Fieulaine, \& W. van Beek (Eds.), Time perspective theory, review, research and application (pp. 57-71). Cham, Switzerland: Springer International.

Taber, B. J. (2013). Time perspective and career decision-making difficulties in adults. Journal of Career Assessment, 21, 200-209. doi:10.1177/1069072712466722

Taber, B. J. (2015). Enhancing future time perspective and exploring occupational possible selves. In P. J. Hartung, M. L. Savickas, \& W. B. Walsh (Eds.), APA handbook of career intervention: Applications (Vol. 2, pp. 101-111). Washington, DC: APA Books.

Taber, B. J., \& Blankemeyer, M. (2015). Future work self and career adaptability in the prediction of proactive career behaviors. Journal of Vocational Behavior, 86, 20-27. doi;10.1016/j.jvb.2014.10.005

Taylor, K. M., \& Betz, N. E. (1983). Applications of self-efficacy theory to the understanding and treatment of career indecision. Journal of Vocational Behavior, 22, 63-81. doi:10.1016/0001-8791(83)90006-4

Verbruggen, M., \& Sels, L. (2010). Social-cognitive factors affecting clients' career and life satisfaction after counseling. Journal of Career Assessment, 18, 3-15. doi:10.1177/1069072709340516

Walker, T. L., \& Tracey, T. G. (2012). The role of future time perspective in career decision-making. Journal of Vocational Behavior, 81, 150-158. doi:10.1016/j.jvb.2012.06.002 
Wentzel, K. R., Muenks, K., Mcneish, D., \& Russell, S. (2017). Peer and teacher supports in relation to motivation and effort: A multi-level study. Contemporary Educational Psychology, 49, 32-45. doi:10.1016/j.cedpsych. 2016.11.002

Wright, S. L., Jenkins-Guarnieri, M. A., \& Murdock, J. L. (2013). Career development among first-year college students: College self-efficacy, student persistence, and academic success. Journal of Career Development, 40, 292-310. doi:10.1177/0894845312455509

Zhang, H., \& Huang, H. (2018). Decision-making self-efficacy mediates the peer support-career exploration relationship. Social Behavior \& Personality: An International Journal, 46, 485-498. doi:10.2224/sbp.6410

Zimbardo, P. G., \& Boyd, J. N. (1999). Putting time in perspective: A valid, reliable individual-differences metric. Journal of Personality and Social Psychology, 77, 1271-1288. doi:10.1037/0022-3514.77.6.1271

Zimbardo, P. G., \& Boyd, J. N. (2008). The time paradox. New York, NY: Free Press.

Zimmerman, B. J. (2013). From cognitive modeling to self-regulation: A social cognitive career path. Educational Psychologist, 48, 135-147. doi:10.1080/00461520.2013.794676

\section{Author Biographies}

Lucia Kvasková received a master's degree in psychology from Comenius University in Bratislava and is a doctoral student in the Developmental Psychology Program at the Masaryk University in Brno. Her research interests include emerging adults' career development in relation to social support, attachment, and personality. Lately, she engages in research on career adaptability of "forgotten half." In her free time, she enjoys traveling, gastronomy, theatre, and running.

Carlos A. Almenara, Bc, MSc, $\mathrm{PhD}$, is a postdoctoral researcher at Universidad Peruana de Ciencias Aplicadas, Peru. His major research interests are body image, eating behavior, disordered eating, eating disorders, e-health, $\mathrm{m}$-health, and the uses of technology for behavior change from a public health perspective. In his leisure time, he enjoys electronic music both as a listener and as an enthusiast composer. $\mathrm{He}$ is also passionate about physical activity, particularly biking and calisthenics. 